\title{
Clinical usefulness of narrow band imaging magnifying colonoscopy for assessing ulcerative colitis-associated cancer/dysplasia
}

Authors

Institutions
Soki Nishiyama', Shiro Oka², Shinji Tanaka ${ }^{2}$, Shintaro Sagami ${ }^{1}$, Ryohei Hayashi ${ }^{1}$, Yoshitaka Ueno ${ }^{2}$, Koji Arihiro ${ }^{3}$, Kazuaki Chayama ${ }^{1}$

${ }^{1}$ Gastroenterology and Metabolism, Graduate School of Biomedical Sciences, Hiroshima University, Hiroshima, Japan

2 Department of Endoscopy, Hiroshima University Hospital, Hiroshima, Japan

${ }^{3}$ Department of Pathology, Hiroshima University Hospital, Hiroshima, Japan submitted 24. March 2016 accepted after revision 22. August 2016

\section{Bibliography}

Dol http://dx.doi.org/ 10.1055/s-0042-116488 Endoscopy International Open 2016; 04: E1183-E1187 (c) Georg Thieme Verlag KG Stuttgart · New York E-ISSN 2196-9736

Corresponding author Shiro Oka, MD, PhD Department of Endoscopy Hiroshima University Hospital 1-2-3 Kasumi, Minami-ku, Hiroshima

Japan

Fax: +81 82-257-5193

oka4683@hiroshima-u.ac.jp
Background and study aims: Colitis-associated cancer/dysplasia (CC/D) can affect the life expectancy of patients with ulcerative colitis (UC). Although the utility of magnifying chromocolonoscopy has been shown, the use of optical magnification with narrow band imaging (NBI) for distinguishing CC/D from non-neoplastic lesions in patients with UC has not been reported. We evaluated whether endoscopic findings are distinguishing and thus assessed the clinical usefulness of NBI magnification for differentiating UC-associated lesions.

Patients and methods: The study involved 27 patients diagnosed and treated at Hiroshima University Hospital between September 2005 and March 2015: a neoplasia group (16 lesions) and a non-neoplasia group (17 lesions). The neoplasias comprised 9 dysplastic lesions, 5 intramucosal carcinomas, and 2 submucosal carcinomas, and 17 non-neoplastic lesions. Targeted biopsy samples of suspicious lesions detected by conventional

\section{Introduction \\ $\nabla$}

Because colitis-associated cancer or dysplasia (CC/D) can affect the life expectancy of patients with ulcerative colitis (UC), it is important that patients considered to be at high risk be placed under close colonoscopic surveillance. Under surveillance colonoscopy (SCS), tumors can be diagnosed at an early stage while they are still completely curable [1]. Because it is often difficult to identify neoplastic lesions with the use of an ordinary endoscope, most endoscopists have considered it necessary to perform blind biopsies [2].

Recently, however, chromocolonoscopy or magnifying colonoscopy with targeted biopsy has come into use for more efficient discovery of neoplastic lesions [3,4]. In Japan, narrow band imaging (NBI) is commonly used for diagnosis of colorectal lesions [5-9]. A large body of literature exists on the utility of NBI for detection of colorectal polyps colonoscopy were classified pathologically as neoplastic or non-neoplastic, and NBI magnifying colonoscopy findings (i.e., the surface [unclear/regular/irregular/amorphous] and vascular [same as the background mucosa/regular/irregular/avascular] patterns) of the 2 lesion types were compared. Results: Irregular/amorphous surface patterns were significantly more common in neoplastic lesions than in non-neoplastic lesions (81\% [13/16] vs. $18 \%$ [3/17], respectively, $P<0.001)$. Irregular/ avascular vessel pattern tended to be more common in neoplastic lesions (75\% [12/16] vs. $41 \%$ [7/ 17], respectively). The surface pattern correctly predicted $82 \%$ of neoplastic lesions, and the vessel pattern correctly predicted $67 \%$ of non-neoplastic lesions. The 2 endoscopic findings together correctly predicted $91 \%$ of neoplastic lesions.

Conclusion: Surface pattern, determined by magnifying colonoscopy with NBI, is useful for differenting between UC-associated neoplastic and non-neoplastic lesions.

and for differential diagnosis between neoplastic and non-neoplastic lesions [5-9]. However, in several previous clinical studies involving UC patients, SCS based on NBI did not provide satisfactory detection of CC/D [3,10-13].

In this retrospective study, we analyzed the endoscopic findings of CC/D and non-neoplastic lesions in UC patients to determine whether particular endoscopic findings distinguish the two abnormalities and thus whether use of magnifying colonoscopy with NBI can preclude the need for biopsy.

\section{Patients and methods \\ $\nabla$ \\ Patients}

Our study involved 33 UC-associated lesions diagnosed consecutively at Hiroshima University Hospital between September 2005 and March 2015. 


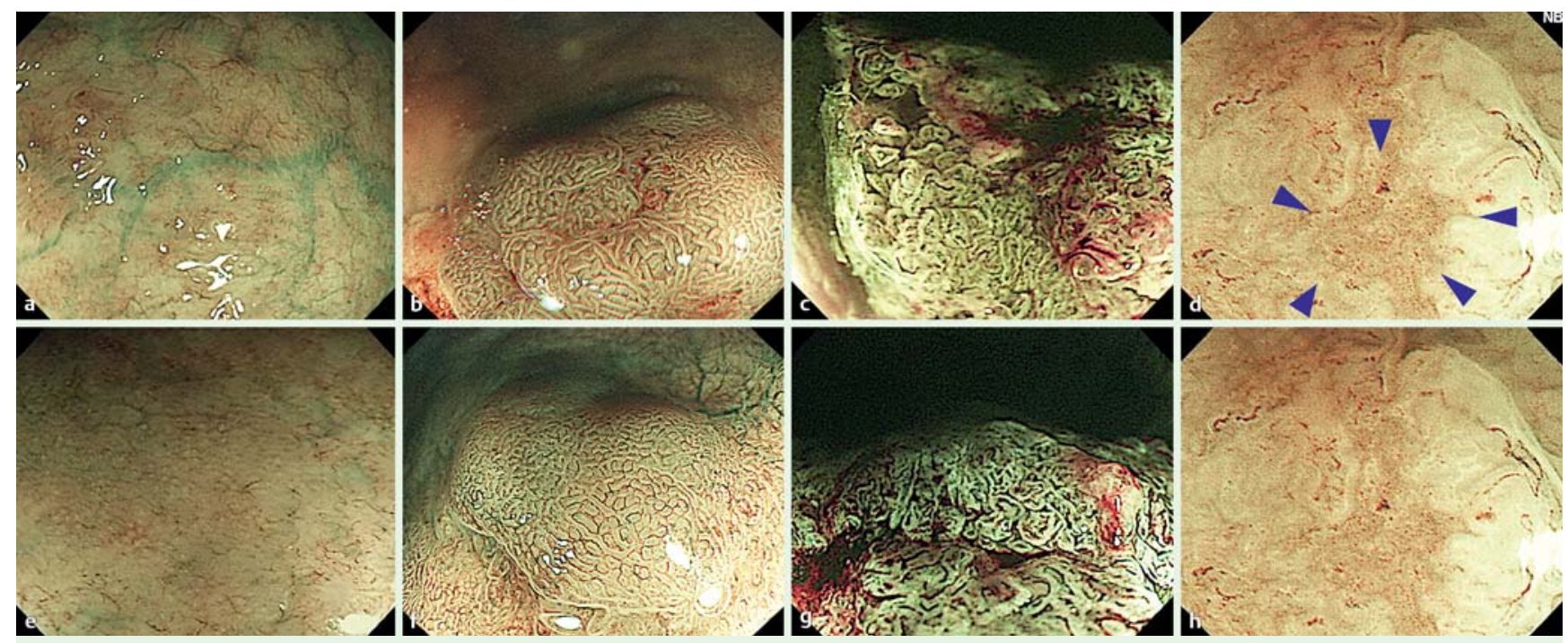

Fig. 1 Findings of ulcerative colitis-associated lesions observed under NBI magnifying colonoscopy. Surface patterns are $\mathbf{a}$ unclear, $\mathbf{b}$ regular, $\mathbf{c}$ irregular, and/ or $\mathbf{d}$ amorphous, and vascular patterns are $\mathbf{e}$ like that of the background mucosa, $\mathbf{f}$ regular, $\mathbf{g}$ irregular, or $\mathbf{h}$ avascular.

We excluded cases with magnifying pictures that we could not evaluate in detail. Targeted biopsy was performed in all cases for suspected CC/D based on conventional colonoscopic findings of lesion colour or presence of a clear boundary. None of the patients included in the study had ever been diagnosed with advanced cancer. Patient characteristics (age, sex, disease duration, type of UC, lesion location and size, and therapy or continued surveillance) were compared between the 2 groups. Use of patient data for the purpose of the study was approved by the Institutional Review Board of Hiroshima University (No.1476).

\section{Histopathologic examination}

All biopsy specimens were fixed in $10 \%$ formalin and embedded in paraffin, serially sectioned, and stained with hematoxylin and eosin (H\&E). In all cases, dysplasia or cancer was confirmed by review, which included more than 1 gastrointestinal pathologist. Immunostaining for p53 and Ki-67 was performed if necessary. Specimens were classified broadly for epithelial changes associated with UC as negative, indefinite, or positive for dysplasia (i.e., potentially malignant neoplasms) according to the histologic system proposed by Riddell et al. [14]. Dysplasia was further classified as high-grade dysplasia or low-grade dysplasia, depending on the degree of cellular abnormality.

\section{Comparison of endoscopic findings between neoplasias} and non-neoplasias associated with UC

The patients had all undergone conventional colonoscopy and magnifying colonoscopy with NBI. Conventional colonoscopy included examination for active inflammation of the mucous membrane, lesion color (same as the background mucosa vs. pale red or bright red), existence of a clear boundary, surface appearance (smooth, granulonodular, villous, or lobular), and hemorrhage, and magnifying colonoscopy with NBI included examination of surface patterns (unclear/regular/irregular/amorphous) and vessel patterns (same as the background mucosa/regular/irregular/ avascular) ( $\bullet$ Fig. 1 ). Magnifying colonoscopy with NBI was performed with a magnifying endoscope (CF-H260AZI, PCFQ260AZI, Olympus, Tokyo, Japan). Endoscopic photography was performed in a blinded manner, and the images obtained during both examinations were interpreted by 5 endoscopists (S.O., S.S.,
R.H., Y.N., S.N.), each with 10 or more years of experience after full graduate training. Findings were adopted when more than 3 endoscopists were in agreement. For cases with differing findings, consensus was obtained after discussion. There was substantial agreement between the different endoscopists diagnosing neoplasia. The doctors who underwent SCS were different from 5 endoscopists in this study.

Lesions were classified as neoplasia $(\mathrm{n}=16)$ or non-neoplasia $(n=17)$ according to the pathological findings. The 16 neoplasias comprised 9 dysplastic lesions, 5 intramucosal carcinomas, and 2 submucosal invasive carcinomas. Both conventional colonoscopy findings and NBI magnifying colonoscopy findings, as noted above, were also compared between the 2 groups.

\section{Statistical analysis}

Values are expressed as mean \pm SD or as percentages. Betweengroup differences in categorical variables were analyzed by chisquare test with Yates correction, and between-group differences in continuous variables were analyzed by Student's $t$-test. $P<0.05$ was considered statistically significant.

\section{Results \\ $\nabla$}

Characteristics of the study patients are shown per group in - Table1. There was no significant difference between the neoplasia group and the non-neoplasia group in disease duration, type of UC, lesion location, lesion size, or type of therapy; only the percentage of patients who did not undergo therapy but rather remained under continued surveillance differed significantly between the two groups. The conventional colonoscopy findings are shown for the total patients and for the neoplasia group and non-neoplasia group in 0 Table2. No significant differences in conventional colonoscopy findings were noted between the neoplasias and the non-neoplasias.

Magnifying colonoscopy with NBI findings of the neoplastic and non-neoplastic lesions are shown in 0 Table 3. An irregular/ amorphous surface pattern was significantly more common in the neoplastic lesions, at $81 \%(13 / 16)$, than in the non-neoplastic lesions, at $18 \%(3 / 17)(P<0.001)$, and irregular and avascular ves- 
Table 1 Characteristics of study patients per study group.

\begin{tabular}{|c|c|c|c|}
\hline Characteristic & $\begin{array}{l}\text { Neoplasia } \\
n=16\end{array}$ & $\begin{array}{l}\text { Non-neoplasia } \\
n=17\end{array}$ & $P$ value \\
\hline Age, mean $\pm S D$ (year) & $59.3 \pm 10.1$ & $49.7 \pm 15.6$ & \\
\hline$<40$ years & $0(0)$ & $5(29)$ & \\
\hline$\geq 40$ years & $16(100)$ & $12(71)$ & NS \\
\hline \multicolumn{4}{|l|}{ Sex } \\
\hline Male & $11(69)$ & $9(53)$ & \\
\hline Female & $5(31)$ & $8(47)$ & NS \\
\hline $\begin{array}{l}\text { Disease duration } \\
(\text { mean } \pm \text { SD) }\end{array}$ & $12.9 \pm 6.2$ & $11.3 \pm 8.8$ & \\
\hline$<7$ years & $2(12)$ & $3(18)$ & \\
\hline$\geq 7$ years & $14(88)$ & $14(82)$ & NS \\
\hline \multicolumn{4}{|l|}{ Type of UC } \\
\hline Total colitis & $13(81)$ & $11(65)$ & \\
\hline Left-sided & $3(19)$ & $6(35)$ & NS \\
\hline Proctitis & $0(0)$ & $0(0)$ & \\
\hline \multicolumn{4}{|l|}{ Location } \\
\hline Rectum & $12(75)$ & $10(59)$ & \\
\hline Sigmoid & $1(6)$ & $5(29)$ & \\
\hline Descending & $3(19)$ & $1(6)$ & NS \\
\hline Transverse & $0(0)$ & $0(0)$ & \\
\hline Cecum/Ascending & $0(0)$ & $1(6)$ & \\
\hline Lesion size (mean $\pm S D$ ) & $19.7 \pm 12.3 \mathrm{~mm}$ & $14.1 \pm 10.5 \mathrm{~mm}$ & NS \\
\hline \multicolumn{4}{|l|}{ Therapy } \\
\hline Surgery & $8(50)$ & $1(6)$ & \\
\hline Endoscopic therapy & $5(31)$ & $0(0)$ & \\
\hline Continued surveillance & $3(19)$ & $16(94)$ & $<0.05$ \\
\hline
\end{tabular}

Number (and percentage) of patients are shown unless otherwise indicated. UC, ulcerative colitis.

sel patterns were more common in the neoplastic lesions than in the non-neoplastic lesions (75\% [12/16] vs. $41 \%$ [7/17], respectively), there was no significant difference in vessel patterns between lesions with and without dysplasia.

Performance of the various NBI magnifying colonoscopy findings are shown in $\bullet$ Table 4 . Surface patterns correctly predicted neo-
Table 3 NBI magnifying endoscopic findings of the lesions per study group.

\begin{tabular}{|c|c|c|c|}
\hline Findings & $\begin{array}{l}\text { Neoplasia } \\
n=16\end{array}$ & $\begin{array}{l}\text { Non-neoplasia } \\
n=17\end{array}$ & $P$ value \\
\hline \multicolumn{4}{|l|}{ Surface pattern } \\
\hline Unclear & $0(0)$ & $9(53)$ & \multirow{4}{*}{$<0.001$} \\
\hline Regular & $3(19)$ & $5(29)$ & \\
\hline Irregular & $10(62)$ & $3(18)$ & \\
\hline Amorphous & $3(19)$ & $0(0)$ & \\
\hline \multicolumn{4}{|l|}{ Vascular pattern } \\
\hline Same as background mucosa & $3(19)$ & $6(35)$ & \\
\hline Regular & $1(6)$ & $4(24)$ & NS \\
\hline Irregular & $11(69)$ & $7(41)$ & \\
\hline Avascular & $1(6)$ & $0(0)$ & \\
\hline
\end{tabular}

Number (and percentage) of lesions are shown unless otherwise indicated.

plasia in $81.8 \%$ of cases, and vessel patterns correctly predicted neoplasia in $66.7 \%$ of cases. We examined the utility of combining the two independent NBI magnifying colonoscopy findings (surface pattern and vessel pattern) for a diagnosis of CC/D. Existence of the 2 findings together correctly predicted neoplasia in $90.9 \%$ of cases.

\section{Discussion}

\section{$\nabla$}

NBI is commonly used in Japan for diagnosis of colorectal lesions. Many investigators have reported the utility of NBI for detection of colorectal polyps and for differential diagnosis between neoplastic and non-neoplastic lesions [5,6,15-17]. However, results of some studies have suggested that NBI magnification is not effective for detection of colorectal neoplasia [3,10-13]. An advantage of NBI magnification is that visualization can be achieved without dye spraying, potentially reducing the cost of examination. Because NBI involves a simple 1-touch operation, NBI magnification may actually shorten the procedure time required for detecting and diagnosing non-polypoid colorectal neoplasms in

\begin{tabular}{|c|c|c|c|c|}
\hline Finding & $\begin{array}{l}\text { Total patients } \\
\mathrm{n}=33\end{array}$ & $\begin{array}{l}\text { Neoplasia } \\
n=16\end{array}$ & $\begin{array}{l}\text { Non-neoplasia } \\
\mathrm{n}=17\end{array}$ & $P$ value \\
\hline \multicolumn{5}{|l|}{$\begin{array}{l}\text { Inflammation of the } \\
\text { Background mucosa }\end{array}$} \\
\hline Active & $17(52)$ & $9(56)$ & $8(47)$ & \\
\hline Inactive & $16(48)$ & $7(44)$ & $9(53)$ & NS \\
\hline \multicolumn{5}{|l|}{ Color } \\
\hline Same as mucosa & $2(6)$ & $0(0)$ & $2(12)$ & \\
\hline Pale & $8(24)$ & $6(37)$ & $2(12)$ & NS \\
\hline Red & $23(70)$ & $10(63)$ & $13(76)$ & \\
\hline \multicolumn{5}{|l|}{ Lesion boundary } \\
\hline Clear & $25(76)$ & $12(75)$ & $13(76)$ & \\
\hline Unclear & $8(24)$ & $4(25)$ & $4(24)$ & NS \\
\hline \multicolumn{5}{|l|}{ Appearance } \\
\hline Smooth & $8(24)$ & $2(13)$ & $6(35)$ & \\
\hline Granulonodular & $14(42)$ & $8(50)$ & $6(35)$ & \\
\hline Villous & $9(27)$ & $5(31)$ & $4(24)$ & NS \\
\hline Lobular & $2(7)$ & $1(6)$ & $1(6)$ & \\
\hline \multicolumn{5}{|l|}{ Hemorrhage } \\
\hline Present & $6(18)$ & $2(12)$ & $4(24)$ & \\
\hline Absent & $27(82)$ & $14(88)$ & $13(76)$ & NS \\
\hline
\end{tabular}

Table 2 Conventional endoscopy findings per study group.

Number (and percentage) of patients are shown. 
Table 4 Performance of the features of magnifying colonoscopy with NBI for diagnosis of colitis-associated cancer/dysplasia.

\begin{tabular}{|c|c|c|c|c|c|}
\hline Individual criteria & $\begin{array}{l}\text { Accuracy } \\
\text { (95\%Cl) }\end{array}$ & $\begin{array}{l}\text { Sensitivity } \\
(95 \% \mathrm{Cl})\end{array}$ & $\begin{array}{l}\text { Specificity } \\
(95 \% \mathrm{Cl})\end{array}$ & $\begin{array}{l}\text { PPV } \\
\text { (95\%Cl) }\end{array}$ & $\begin{array}{l}\text { NPV } \\
(95 \% \mathrm{Cl})\end{array}$ \\
\hline Surface pattern & $\begin{array}{l}81.8 \% \\
(65.6-91.4)\end{array}$ & $\begin{array}{l}81.3 \% \\
(64.5-91.1)\end{array}$ & $\begin{array}{l}82.4 \% \\
(66.6-91.6)\end{array}$ & $\begin{array}{l}81.3 \% \\
(64.5-91.1)\end{array}$ & $\begin{array}{l}82.4 \% \\
(66.6-91.6)\end{array}$ \\
\hline Vascular pattern & $\begin{array}{l}66.7 \% \\
(49.8-79.3)\end{array}$ & $\begin{array}{l}75.0 \% \\
(57.6-88.1)\end{array}$ & $\begin{array}{l}58.8 \% \\
(42.5-71.1)\end{array}$ & $\begin{array}{l}63.2 \% \\
(48.5-74.2)\end{array}$ & $\begin{array}{l}71.4 \% \\
(51.6-86.3)\end{array}$ \\
\hline $\begin{array}{l}\text { Surface pattern } \\
\text { + vascular pattern }\end{array}$ & $\begin{array}{l}90.9 \% \\
(76.5-95.8)\end{array}$ & $\begin{array}{l}93.8 \% \\
(78.9-98.8)\end{array}$ & $\begin{array}{l}88.2 \% \\
(74.3-92.9)\end{array}$ & $\begin{array}{l}88.2 \% \\
(74.3-92.9)\end{array}$ & $\begin{array}{l}93.8 \% \\
(78.9-98.8)\end{array}$ \\
\hline
\end{tabular}

Surface pattern: irregular, amorphous; vascular pattern: irregular, avascular.

PPV, positive predictive value; NPV, negative predictive value; $95 \% \mathrm{Cl}, 95 \%$ confidence interval.

patients with inflammatory bowel disease, boosting the efficiency of SCS. The major limitation of NBI is that the visual field becomes too dark during its application. A new-generation NBI system with improved brightness has been developed, but prospective trials for diagnosis of CC/D in UC patients have not been performed.

In previous clinical studies on the utility of NBI colomoscopy for detecting CC/D in UC patients, SCS with NBI did not yield satisfactory results [3,10-13], and no significant difference in the ability to detect CC/D was found between NBI and white light endoscopy. Dekker et al. [11] reported detection of 52 suspicious lesions in 17 patients during NBI endoscopy vs. 28 suspicious lesions in 13 patients during white light endoscopy. Pathologic evaluation of the target biopsy specimens revealed neoplastic lesions in 11 patients in total. Neoplastic lesions were detected by both techniques in 4 of the 11 patients, by NBI endoscopy alone in 4 of the 11 patients, and by white light endoscopy alone in 3 of the 11 patients. van den Broek et al. [18] reported that 11 of 16 (69\%) neoplastic lesions were detected by white light endoscopy and that 13 of the $16(81 \%)$ were detected by NBI endoscopy, without a significant difference between the 2 methods. Efthymiou et al. [19] reported detection of 131 (92\%) lesions by chromoendoscopy in contrast to detection of 102 lesions $(70 \%)$ by NBI $(P<0.001)$, and the median number of lesions detected per patient was 3 with chromoendoscopy and 1.5 with NBI $(P=0.002)$.

NBI was not used with optical magnification in these clinical studies. We have thus have continued to study the use of NBI magnifying colonoscopy in our unit in Hiroshima. Some reports have suggested that the NBI magnifying observation of UCI is useful for discriminating between dysplastic/neoplastic and non-neoplastic lesions and for determining the need for target biopsy. East et al. [10] found that dysplasias were characteristically darkened by obvious capillary vascular. Matsumoto et al. [12] reported that a tortuous surface structure identified upon NBI magnification might serve as a clue for the identification of dysplasia during SCS for UC patients. We have reported the clinical usefulness of NBI magnification for qualitative diagnosis of sporadic colorectal lesions by combined evaluation of both the surface pattern and microvessel findings [5]. The surface pattern is thought to be more useful endoscopic findings because inflammation is accompanied by disruption of the microvessel structure. In this study, we focused on surface and vessel patterns observed under NBI magnifying colonoscopy. Our analysis showed that surface pattern, as determined by NBI magnifying colonoscopy, is useful for differentiation between CC/D and non-neoplastic lesions. It will be necessary to study these findings prospectively to clarify whether or not they are diagnostically effective.
Successful diagnosis based on pit patterns observed under magnifying chromocolonoscopy has been reported in patients with UC [3,4,20-25]. Hata et al. [20] reported finding no neoplastic lesions in regions characterized by type I or II pit patterns. They in fact found such lesions only in association with type $\mathrm{III}_{\mathrm{L}}$, type IV, and type $\mathrm{V}$ pit patterns. However, they did note type III and IV patterns on some non-neoplastic flat lesions. Therefore, the current pit pattern classification system may not be fully applicable in cases of UC. The pit pattern of the regenerative hyperplastic villous mucosa in UC is difficult to distinguish from neoplastic pit patterns because the pits characteristic of UC can become elongated or irregular, depending on the degree of inflammation [26]. We have reported instead that discovery of a high residual density of pits and irregular pit margins upon magnification after indigo carmine dye spraying is useful for differentiating between colitis-associated neoplastic and non-neoplastic lesions [21].

Other investigators have mentioned the use of endoscopic autofluorescence imaging (AFI), by which CC/D is observed as a slight magenta region despite being invisible to the naked eye [27]. According to prospective AFI-based trials [28], the reported sensitivity for neoplastic lesions is approximately $86 \%$, but the reported specificity is extremely low, and distinguishing between inflamed mucous membranes and neoplastic lesions may be problematic.

\section{Conclusion}

In conclusion, the surface pattern, as determined by NBI magnifying colonoscopy, is a useful finding for differentiation between colitis-associated neoplastic and non-neoplastic lesions. We acknowledge that the surface pattern cannot be used to replace biopsy for diagnosis. However, being able to differentiate dysplastic lesions from non-dysplastic lesions can potentially help endoscopists take smarter biopsies and increase the diagnostic yield. Larger studies should be performed to evaluate the clinical utility of NBI magnifying colonoscopy for SCS.

\section{Competing interests: None}

\section{Acknowledgements \\ $\nabla$}

This study was conducted with a Grant-in-Aid from the Japan Agency for Medical Research and Development, AMED (15ck0106102h0102). 


\section{References}

1 Eaden JA, Abrams KR, Mayberry JF. The risk of colorectal cancer in ulcerative colitis: a meta-analysis. Gut 2001; 48: 526-535

2 Magro F, Langner C, Driessen A et al. European consensus on the histopathology of inflammatory bowel disease. J Crohns Colitis 2013; 7: $827-851$

3 Oka S, Tanaka S, Chayama K et al. Detection of nonpolypoid colorectal neoplasia using magnifying endoscopy in colonic inflammatory bowel disease. Gastrointest Endosc Clin N Am 2014; 24: 405-417

4 Ueno Y, Tanaka S, Chayama K. Non-polypoid colorectal neoplasms in ulcerative colitis. Gastrointest Endosc Clin N Am 2010; 20: 525-542

5 Hirata M, Tanaka S, Oka S et al. Magnifying endoscopy with narrow band imaging for diagnosis of colorectal tumors. Gastrointest Endosc 2007; 65: 988-995

6 Tanaka S, Sano Y. Aim to unify the narrow band imaging (NBI) magnifying classification for colorectal tumors: current status in Japan from a summary of the consensus symposium in the 79th Annual Meeting of the Japan Gastroenterological Endoscopy Society. Dig Endosc 2011; 23: $131-139$

7 Oba S, Tanaka S, Sano Y et al. Current status of narrow-band imaging magnifying colonoscopy for colorectal neoplasia in Japan. Digestion 2011; 83: 167-172

8 Hayashi $N$, Tanaka S, Hewett DG et al. Endoscopic prediction of deep submucosal invasive carcinoma: validation of the narrow-band imaging international colorectal endoscopic (NICE) classification. Gastrointest Endosc 2013; 78: 625-632

9 Tanaka S, Hayashi N, Oka S et al. Endoscopic assessment of colorectal cancer with superficial or deep submucosal invasion using magnifying colonoscopy. Clin Endosc 2013; 46: 138-146

10 East JE, Suzuki N, von Herbay A et al. Narrow band imaging with magnification for dysplasia detection and pit pattern assessment in ulcerative colitis surveillance: a case with multiple dysplasia associated lesions or masses. Gut 2006; 55: 1432-1435

11 Dekker E, van den Broek FJ, Reitsma JB et al. Narrow-band imaging compared with conventional colonoscopy for the detection of dysplasia in patients with longstanding ulcerative colitis. Endoscopy 2007; 39: $216-221$

12 Matsumoto T, Kudo T, Jo $Y$ et al. Magnifying colonoscopy with narrow band imaging system for the diagnosis of dysplasia in ulcerative colitis: a pilot study. Gastrointest Endosc 2007; 66: 957-965

13 Pellisé M, López-Cerón M, Rodríguez de Miguel C et al. Narrow-band imaging as an alternative to chromoendoscopy for the detection of dysplasia in long-standing inflammatory bowel disease: a prospective, randomized, crossover study. Gastrointest Endosc 2011; 74: 840-848

14 Riddell RH, Goldman H, Ransohoff DF et al. Dysplasia in inflammatory bowel disease: standardized classification with provisional clinical applications. Hum Pathol 1983; 14: 931 - 968
15 Tischendorf JJ, Schirin-Sokhan R, Streetz K et al. Value of magnifying endoscopy in classifying colorectal polyps based on vascular pattern. Endoscopy 2010; 42: 22-27

16 Henry ZH, Yeaton P, Shami VM et al. Meshed capillary vessels found on narrow-band imaging without optical magnification effectively identifies colorectal neoplasia: a North American validation of the Japanese experience. Gastrointest Endosc 2010; 72: 118-126

17 Rastogi A, Pondugula K, Bansal A. Recognition of surface mucosal and vascular patterns of colon polyps by using narrow-band imaging: interobserver and intraobserver agreement and prediction of polyp histology. Gastrointest Endosc 2009; 69: 716 - 722

18 van den Broek FJ, Fockens P, van Eeden S et al. Narrow-band imaging versus high-definition endoscopy for the diagnosis of neoplasia in ulcerative colitis. Endoscopy 2011; 43: $108-115$

19 Efthymiou M, Allen PB, Taylor AC et al. Chromoendoscopy versus narrow band imaging for colonic surveillance in inflammatory bowel disease. Inflamm Bowel Dis 2013; 19: $2132-2138$

20 Hata $K$, Watanabe T, Motoi $T$ et al. Pitfalls of pit pattern diagnosis in ulcerative colitis-associated dysplasia. Gastroenterology 2004; 126 : $374-376$

21 Nishiyama S, Oka S, Tanaka $S$ et al. Is it possible to discriminate between neoplastic and non-neoplastic lesions in ulcerative colitis by magnifying colonoscopy? Inflamm Bowel Dis 2014; 20: 508-513

22 Hurlstone DP, Sanders DS, Lobo AJ et al. Indigo carmine-assisted highmagnification chromoscopic colonoscopy for the detection and characterisation of intraepithelial neoplasia in ulcerative colitis: a prospective evaluation. Endoscopy 2005; 37: 1186-1192

23 Matsumoto T, Nakamura S, Jo $Y$ et al. Chromoscopy might improve diagnostic accuracy in cancer surveillance for ulcerative colitis. Am J Gastroenterol 2003; 98: 1827-1833

24 Marion JF, Waye JD, Present DH et al. Chromoendoscopy-targeted biopsies are superior to standard colonoscopic surveillance for detecting dysplasia in inflammatory bowel disease patients: a prospective endoscopic trial. Am J Gastroenterol 2008; 103: 2342-2349

25 Sada M, Igarashi M, Yoshizawa $S$ et al. Dye spraying and magnifying endoscopy for dysplasia and cancer surveillance in ulcerative colitis. Dis Colon Rectum 2004; 47: 1816-1823

26 Kunihiro M, Tanaka S, Sumii M et al. Magnifying colonoscopic features of ulcerative colitis reflect histologic inflammation. Inflamm Bowel Dis 2004; 10: 737-744

27 Matsumoto T, Nakamura S, Moriyama T et al. Autofluorescence imaging colonoscopy for the diagnosis of dysplasia in ulcerative colitis. Inflamm Bowel Dis 2007; 13: 640-641

28 Matsumoto T, Nakamura S, Moriyama T et al. Autofluorescence imaging colonoscopy for the detection of dysplastic lesions in ulcerative colitis: a pilot study. Colorectal Dis 2010; 12: 291-297 